\title{
Evaluation of breath, plasma, and urinary markers of lactose malabsorption to diagnose lactase non-persistence following lactose or milk ingestion
}

\author{
Aahana Shrestha ${ }^{1,2}$, Matthew P. G. Barnett ${ }^{2,3,4}$, Jo K. Perry ${ }^{1}$, David Cameron-Smith ${ }^{1,2,5}$ and Amber M. Milan ${ }^{1,3,4^{*}}$ (D)
}

\begin{abstract}
Background: Adult lactase non-persistence (LNP) is due to low lactase expression, resulting in lactose malabsorption (LM). LNP is a genetic trait, but is typically determined by LM markers including breath $\mathrm{H}_{2}$, blood glucose, and urinary galactose after a lactose tolerance test. Known validity of these markers using milk is limited, despite being common practice. Compositional variation, such as $\beta$-casein variants, in milk may impact diagnostic efficacy. This study aimed to evaluate the diagnostic accuracy to detect LNP using these commonly measured LM markers after both lactose and milk challenges.
\end{abstract}

Methods: Fourty healthy young women were challenged with $50 \mathrm{~g}$ lactose then randomized for separate crossover visits to ingest $750 \mathrm{~mL}$ milk (37.5 g lactose) as conventional (both A1 and A2 $\beta$-casein) and A1 $\beta$-casein-free (a2 Milk ${ }^{T M}$ ) milk. Blood, breath and urine were collected prior to and up to $3 \mathrm{~h}$ following each challenge. The presence of $C / T_{13910}$ and $G / A_{22018}$ polymorphisms, determined by restriction fragment length polymorphism, was used as the diagnostic reference for LNP.

Results: Genetic testing identified 14 out of 40 subjects as having LNP $\left(C / C_{13910}\right.$ and $\left.G / G_{22018}\right)$. All three $L M$ markers (breath $\mathrm{H}_{2}$, plasma glucose and urinary galactose/creatinine) discriminated between lactase persistence (LP) and LNP following lactose challenge with an area under the receiver operating characteristic (ROC) curve (AUC) of $1.00,0.75$ and 0.73 , respectively. Plasma glucose and urinary galactose/creatinine were unreliable (AUC $<0.70)$ after milk ingestion. The specificity of breath $\mathrm{H}_{2}$ remained high (100\%) when milk was used, but sensitivity was reduced with conventional (92.9\%) and a2 Milk $\mathrm{K}^{\mathrm{TM}}$ (78.6\%) compared to lactose (sensitivities adjusted for lactose content). The breath $\mathrm{H}_{2}$ optimal cut-off value was lower with a2 Milk ${ }^{\mathrm{TM}}(13 \mathrm{ppm})$ than conventional milk (21 ppm). Using existing literature cut-off values the sensitivity and specificity of breath $\mathrm{H}_{2}$ was greater than plasma glucose to detect LNP following lactose challenge whereas values obtained for urinary galactose/creatinine were lower than the existing literature cut-offs.

\footnotetext{
* Correspondence: a.milan@auckland.ac.nz

'The Liggins Institute, The University of Auckland, Auckland, New Zealand

${ }^{3}$ Food Nutrition \& Health Team, AgResearch Limited, Palmerston North, New

Zealand

Full list of author information is available at the end of the article
}

(c) The Author(s). 2020 Open Access This article is licensed under a Creative Commons Attribution 4.0 International License, which permits use, sharing, adaptation, distribution and reproduction in any medium or format, as long as you give appropriate credit to the original author(s) and the source, provide a link to the Creative Commons licence, and indicate if changes were made. The images or other third party material in this article are included in the article's Creative Commons licence, unless indicated otherwise in a credit line to the material. If material is not included in the article's Creative Commons licence and your intended use is not permitted by statutory regulation or exceeds the permitted use, you will need to obtain permission directly from the copyright holder. To view a copy of this licence, visit http://creativecommons.org/licenses/by/4.0/. The Creative Commons Public Domain Dedication waiver (http://creativecommons.org/publicdomain/zero/1.0/) applies to the data made available in this article, unless otherwise stated in a credit line to the data. 
(Continued from previous page)

Conclusion: This study showed accurate diagnosis of LNP by breath $\mathrm{H}_{2}$ irrespective of the substrate used, although the diagnostic threshold may vary depending on the lactose substrate or the composition of the milk.

Trial registration: ACTRN12616001694404. Registered prospectively on December 9, 2016.

Keywords: Lactose malabsorption, Single nucleotide polymorphism, Urinary galactose, Breath $\mathrm{H}_{2}$, Milk

\section{Background}

Lactose, the predominant disaccharide in milk, is readily hydrolysed by the small intestinal enzyme lactase, liberating the constituent glucose and galactose [1]. However, in the majority of the non-northern European population, the expression of this enzyme is suppressed in early childhood, resulting in lactase non-persistence (LNP) [2]. With lactose ingestion, LNP results in lactose malabsorption (LM), and in some individuals, this undigested lactose contributes to the adverse digestive symptoms causing lactose intolerance (LI) [3].

LI can be avoided through exclusion of dietary lactose; however, intolerance to other foods, such as short chain carbohydrates and polyols (fermentable oligosaccharides, disaccharides, monosaccharides and polyols, or FODMAPs) [4] or proteins like gluten [5] or casein [6], can also result in similar digestive symptoms such as bloating, flatulence, diarrhoea, abdominal pain, rumbling, and distension. Therefore, confirmation of LM is required to limit unnecessary avoidance of dairy foods, given their importance for a balanced diet [1, 7] and the potential for micronutrient deficiency with dairy avoidance [8]. Different methods are currently used to diagnose LNP, of which measuring lactase activity in an intestinal biopsy is the proposed "gold standard" $[9,10]$. However, this is an invasive technique for a relatively minor condition. Other more readily measurable, cost-effective and less invasive methods are therefore preferred $[11,12]$.

The minority of the adult population maintains lactase expression, known as lactase persistence (LP). Defined genetic polymorphisms have been identified which are associated with continued lactase expression. For example, two single nucleotide polymorphisms (SNPs) upstream from the $L C T$ locus $\left(\mathrm{C} / \mathrm{T}_{13910}\right.$ and $\left.\mathrm{G} / \mathrm{A}_{22018}\right)$ of the minichromosomal maintenance complex component 6 (MCM6) gene are highly associated with LP [13]. Homozygotes $\left(\mathrm{TT}_{13910}\right.$ and $\left.\mathrm{AA}_{22018}\right)$ or heterozygotes $\left(\mathrm{CT}_{13910}\right.$ and $\left.\mathrm{GA}_{22018}\right)$ show continued lactase activity (LP) whereas the wild type $\left(\mathrm{CC}_{13910}\right.$ and $\left.\mathrm{GG}_{22018}\right)$ results in a loss of lactase activity (LNP), as demonstrated in primarily Caucasian populations [14, 15]. Genotyping these SNPs enables accurate diagnosis of LNP and is preferable to intestinal biopsy; however, genotyping remains expensive and has limited applicability to populations and ethnicities for whom LNP-associated polymorphisms may vary [16]. Genotyping is also ineffective for secondary LM, sometimes present with gastrectomy [17] or other gastrointestinal diseases including celiac disease [18] and Crohn's disease [19] where the cause is damage to the intestine rather than genetic alteration of lactase expression [20].

Other indirect methods used include measurement of breath hydrogen $\left(\mathrm{H}_{2}\right.$; which indicates fermentation of undigested lactose from colonic bacteria [21, 22]), blood glucose and urinary galactose, indicating hydrolysis of lactose. An incremental rise in breath $\mathrm{H}_{2}$ above $20 \mathrm{ppm}$ [23-25] and reduction of plasma glucose below 1.11 $\mathrm{mmol} / \mathrm{L}$ following lactose challenge $[12,26]$ indicate LM or LNP. Urinary galactose is frequently reported using a variety of testing procedures and reporting methods [27-30] limiting direct comparisons within the literature. Grant et al. [28] proposed that a urinary galactose/ creatinine ratio after pooled $3 \mathrm{~h}$ collection provided the best discrimination; on this basis, a threshold of $0.1 \mathrm{mg} /$ mg has been applied by subsequent studies as an absolute threshold [27, 28, 30] or lactose dose extrapolation [31]. Although these indirect measures of LNP depend on the lactose dose [23, 32] and substrate used (e.g. milk) [32], validity and cut-off value specific to the substrate and dose have not been validated [32, 33].

Lactose in its pure form or present in milk may be digested differently [34] but is used interchangeably to diagnose LM [25, 32, 33, 35, 36]. For consumers, milk is more accessible than purified lactose, and with the availability of personal devices like AIRE to detect LM [37], may be a simple method for at-home testing. Moreover, it has been argued that milk is a more physiologically relevant and realistic substrate than lactose for assessing LM $[32,36]$. Milk has been used as a substrate in a variety of studies to establish LM [25, 32, 33, 35, 36]. However, LM and LI symptoms may be influenced by the food matrix or rate of digestion [38] thus, digestive responses may vary between isolated lactose and milk. The presence of other components in milk such as fats [32] may reduce gastric emptying thus influencing LM markers [32, 34]. More importantly, diagnostic thresholds of LM measures using milk have not been validated $[32,33]$. Recent studies have also highlighted that milk protein variants arising from species [39] or breed differences [40] may impact digestion and malabsorption. Notably, the predominant $\beta$-casein variants, A1 and A2 $\beta$-casein, are hypothesised to differentially impact LM 
[31, 35], suggesting that LM markers may perform differently depending on milk protein, or specifically A1 $\beta$ casein, content.

This study aimed to establish the diagnostic accuracy of LM measures (breath $\mathrm{H}_{2}$, plasma glucose, and urinary galactose/creatinine) to diagnose LNP using genotyping (LCT $\mathrm{C} / \mathrm{T}_{13901}$ and $\mathrm{G} / \mathrm{A}_{22018} \mathrm{SNPs}$ ) as a reference method following both lactose and milk challenges. Furthermore, the study aimed to establish diagnostic thresholds following milk with differing $\beta$-casein types.

\section{Methods}

\section{Study design}

We conducted a double blinded randomized cross over study in healthy young women aged $18-30$ years. The primary outcome of the study, reported elsewhere, was to investigate digestive comfort experienced by dairy intolerant individuals following ingestion of lactose and milk with differing bovine $\beta$-casein variants [41]. In total, 40 young women were recruited from the community, 30 of whom self-reported digestive symptoms with milk consumption [42] and 10 who were recruited as dairy tolerant controls, reporting no symptoms with milk consumption. The exclusion criteria included individuals with a BMI below 18 or above $28 \mathrm{~kg} / \mathrm{m}^{2}$, use of antibiotics in the preceding 3 months, gastrointestinal disease (coeliac or inflammatory bowel diseases), or milk allergy. All participants provided written informed consent before the enrolment for the study and were compensated for their time. This study was conducted according to the Declaration of Helsinki and approved by the New Zealand Health and Disability Ethics Committees (Reference no.16/STH/175). Prospective clinical trial registration was registered at www.anzctr.org.au (ACTR N12616001694404). This study adheres to the CONSORT guidelines [43].

\section{Lactose and milk challenges}

Prior to their visits, participants avoided dairy products for at least one week and fibre rich foods for $24 \mathrm{~h}$. Following a standardized low fibre dinner and overnight fast of at least $8 \mathrm{~h}$, participants attended the clinical unit in the morning on 3 occasions separated by at least 1 week. The study was conducted at the Liggins Institute, University of Auckland, between January and May 2017. A standardized lactose challenge was administered on the 1st visit which involved consumption of $50 \mathrm{~g}$ lactose (100\% pure, Midwest Pharmaceutics, New Zealand) dissolved in $250 \mathrm{~mL}$ water. Although a lactose dose of $25 \mathrm{~g}$ is typical for a challenge [23-25] a higher load of $50 \mathrm{~g}$ $[12,22]$ confirms low lactase levels in lactose malabsorbers, without negatively affecting lactose absorbers [3]. On the subsequent three visits, subjects consumed, in a randomised sequence, $750 \mathrm{~mL}$ of a2 Milk $^{\mathrm{ma}}$ (A2M) or conventional (CON) milk (both of which contained 37.5 $\mathrm{g}$ lactose) or lactose-free conventional milk (which contained both A1 and A2 $\beta$-casein but no lactose). However, this study reports secondary outcomes relevant only to lactose malabsorption and lactose containing milks, so does not report on data collected after the lactose-free milk. The sequence of milk treatment arms was randomly generated by www.randomizer.org, blocked by tolerance group, and sealed envelopes were used to allocate the treatment before the first milk tolerance test. Both the participants and researchers were blinded. For all four visits, blood, breath, and urine samples were collected from subjects prior to lactose or milk consumption (baseline) and at frequent intervals for $3 \mathrm{~h}$. Exhaled breath was collected every $15 \mathrm{~min}$ until $2 \mathrm{~h}$ then every $30 \mathrm{~min}$ for $3 \mathrm{~h}$; blood was collected every $30 \mathrm{~min}$ until $3 \mathrm{~h}$, and urine was collected continuously for $3 \mathrm{~h}$.

\section{Blood collection and sampling}

Venous blood was collected in EDTA containing tubes (Becton Dickinson \& Company, Mount Wellington, New Zealand). Peripheral blood mononuclear cells (PBMCs) were extracted immediately from EDTA treated whole blood using Ficoll, as described previously [44] then stored at $-80^{\circ} \mathrm{C}$ until DNA was extracted. Plasma was prepared from EDTA-treated whole blood through centrifugation at $2000 \times \mathrm{g}$ for $15 \mathrm{~min}$ at $4{ }^{\circ} \mathrm{C}$ and frozen at $-80^{\circ} \mathrm{C}$ prior to analyses.

\section{Genetic test: $C / T_{13910}$ and $G / A_{22018}$ genotyping}

DNA was isolated from PBMCs with the universal all Prep kit (Qiagen, Hilden, Germany) as per manufacturer's protocol. LNP genotyping was determined by restriction fragment length polymorphism (RFLP) of polymerase chain reaction (PCR) amplified DNA. For C/ $\mathrm{T}_{13910}$ forward primer $5^{\prime}$-GGACATACTAGAATTCAC TGCAA and reverse primer 5'-GGTTGAAGCGAAGA TGGGACG [45] were used. For $\mathrm{G} / \mathrm{A}_{22018}$, the forward primer 5'-TAGCTGGGACCACAAGCACC and reverse primer 5'-GAAGTCAGAATACCCCTACCC were used as described [41]. The amplification product for $\mathrm{C} / \mathrm{T}_{13910}$ was digested with BsmF1 (New England Biolabs, Foster City, CA) while G/A $\mathrm{A}_{22018}$ was digested with Hha1 (New England Biolabs, Foster City, CA) as per the manufacturer's protocol. The digested products along with the PCR products were visualized using ethidium bromide in 5\% MetaPhor agarose gel (Lonza, Basel, Switzerland) and visualised using ethidium bromide. The results were confirmed by Sanger sequencing. Further details regarding the genotyping procedure are described elsewhere [41].

\section{Malabsorption marker methods}

Hydrogen in the exhaled breath was measured in parts per million (ppm) using a breath analyser (Quintron, 
Milwaukee, WI, USA). Plasma glucose and urinary creatinine were measured using a Roche Cobas $\mathrm{C} 311$ by enzymatic colorimetric assay (Roche, Manheim, Germany). Urinary galactose was measured using the Amplex Red Galactase Oxidase Assay Kit (Molecular Probes, Eugene, Oregon, USA) according to the manufacturer's protocol.

\section{Statistical analysis}

Values are presented as mean \pm SEM or $95 \% \mathrm{CI}$, as indicated. For all malabsorption markers, the change from baseline was calculated providing a single value for each subject. Comparisons between subject groups were computed by linear mixed model using subject as a random factor to account for repeated sampling as required. Outliers were identified as greater than Q3 + 3IQR. Statistical analyses were computed using $\mathrm{R}$ software (version 3.5.2) [46]. Alpha was set at 0.05 .

Sample size was calculated for the primary outcome as described elsewhere [41]. Based on $80 \%$ power, $\alpha=0.05$, to detect an $\mathrm{AUC}=0.80$ [47], we determined that 10 cases and 10 controls would be sufficient. A similar study of diagnostic accuracy of a new test for diagnosing hypolactasia had 30 participants, but only with $\mathrm{AUC}=$ 0.75 [12]

\section{LNP classification methods}

Two polymorphisms $\left(\mathrm{C} / \mathrm{T}_{13910}\right.$ and $\left.\mathrm{G} / \mathrm{A}_{22018}\right)$ of the LCT genotype were used as the reference standard for detecting LNP; binary classification was used to differentiate the LNP genotype $\left(\mathrm{CC}_{13910} / \mathrm{GG}_{22018}\right)$ from LP genotypes $\left(\mathrm{TT}_{13910} / \mathrm{AA}_{22018}\right.$ homozygotes and $\mathrm{CT}_{13910} /$ $\mathrm{GA}_{22018}$ heterozygotes) $[12,48]$. The baseline characteristics between the LCT genotypes (homozygous LNP, homozygous LP and heterozygous LP) were compared using one-way analysis of variance (ANOVA).

\section{Determination of validity of malabsorption marker method} The validity of the malabsorption marker methods was evaluated by the sensitivity, specificity, positive predictive value (PPV), negative predictive value (NPV), false positive (FP) and false negative (FN) [49]. The sensitivity of a test refers to the ability of the test to correctly classify an individual as diseased (true positive) whereas the specificity of a test refers to the ability of the test to detect individuals as disease-free (true negative) [50]. PPV is the probability that a subject with a positive test truly has the disease and NPV is the probability that a subject with a negative test truly does not have the disease [51]. FP is a type I error that indicates a disease exists when it actually does not. FN is a type II error that indicates a disease does not exist when it actually does [49].

\section{Diagnostic accuracy and predicted cut-offs}

Using the LCT genotype as the reference standard [12, 52] the diagnostic accuracy of the malabsorption marker methods was evaluated by receiver operating characteristic (ROC) curve as assessed by area under the ROC curve (AUC) using the pROC package in $\mathrm{R}$ software. A larger AUC indicates a better diagnostic outcome, such that $0.70<\mathrm{AUC}<0.80$ was considered 'acceptable', $0.80<$ AUC $<0.90$ as 'excellent' and AUC $>0.90$ as 'outstanding' [47]. The discriminating ability of the test is determined when the ROC curve differs significantly $(p<0.05)$ from AUC 0.5 (i.e. no discrimination between true positive (TP; LNP) and true negative (TN; LP) [52]) using the Mann-Whitney $U$ test. Differences between ROC curve AUCs were compared across substrates using the ROC test by bootstrap method. Optimal cutoff values using milk as a substrate were calculated by the Youden index for malabsorption markers with an acceptable AUC $>0.70$.

\section{Validity of literature cut-offs}

To compare with literature, an increase over baseline in breath $\mathrm{H}_{2} \geq 20 \mathrm{ppm}$ blood glucose $\leq 1.11 \mathrm{mmol} / \mathrm{L}$ [12, $26]$ and postprandial galactose/creatinine ratio at $\leq 0.10$ $\mathrm{mg} / \mathrm{mg}$ [28] were taken as the cut-off values to diagnose LM (Table 1), and were then compared against the genotype results. For the standardised lactose challenge, classification of LNP and LP using malabsorption markers (breath $\mathrm{H}_{2}$, plasma glucose, and urinary galactose/creatinine ratio) was determined based on diagnostic cut-offs previously reported in literature (Table 1). Following milk consumption, cut-offs for breath $\mathrm{H}_{2}$, plasma glucose [32] and urinary galactose/creatinine ratio [31] were additionally adjusted for the dose of lactose consumed; this approach has previously been used in literature when using milk as a substrate [32, 35]. Similarly, as breath $\mathrm{H}_{2}$ has often been assumed to increase linearly with the dose of lactose consumed [23], the literature cut-off after milk was also adjusted for lactose dose: 15 ppm from $20 \mathrm{ppm}$, based on $37.5 \mathrm{~g}$ lactose in $750 \mathrm{~mL}$ of milk. The validity of the breath $\mathrm{H}_{2}$ was assessed with and without the adjusted value.

Table 1 Diagnostic cut-off for lactose malabsorption based on literature

\begin{tabular}{ll}
\hline Measure & Cut-off for lactose malabsorption ${ }^{1}$ \\
\hline Breath $\mathrm{H}_{2}$ & $\geq 20 \mathrm{ppm}$ \\
Plasma glucose & $\leq 1.11 \mathrm{mmol} / \mathrm{L}$ \\
Urinary galactose/creatinine ratio & $\leq 0.10 \mathrm{mg} / \mathrm{mg}$ \\
\hline
\end{tabular}

Cut-off values are based on validated methods for maximal increase in breath $\mathrm{H}_{2}[23-25]$ and plasma glucose $[12,26]$ over baseline and urinary galactose/ creatinine ratio [28] at $180 \mathrm{~min}$, following ingestion of $50 \mathrm{~g}$ of lactose 
The agreement between the genotype classification and literature-based malabsorption marker classification was determined using Cohen's kappa coefficient.

\section{Results}

\section{Participant characteristics}

The majority of the participants were self-described as Caucasian $(n=25)$, with a minority of South Asian $(n=4)$, Chinese $(n=8)$, Māori $(n=1)$ and South African $(\mathrm{n}=2)$ descent. There were no significant differences in age, BMI, glucose, insulin, and triglycerides at fasting between the three genotypes $(p>0.05$, Table 2$)$.

\section{Lactase genotyping}

There was $100 \%$ agreement between the $\mathrm{C} / \mathrm{T}_{13910}$ and $\mathrm{G} /$ $\mathrm{A}_{22018}$ genotypes. Of the 40 individuals, 14 (35\%) were LNP homozygotes $\left(\mathrm{CC}_{13910} / \mathrm{GG}_{22018}\right)$, and 26 were LP, consisting of 16 (40\%) LP homozygotes $\left(\mathrm{TT}_{13910} / \mathrm{AA}_{22018}\right)$ and 10 (25\%) LP heterozygotes $\left(\mathrm{CT}_{13910} / \mathrm{GA}_{22018}\right)$.

\section{Malabsorption marker difference between LP and LNP individuals with lactose or milk consumption}

All the malabsorption markers measured (breath $\mathrm{H}_{2}$, plasma glucose and urinary galactose/creatinine ratio) differed between LP and LNP individuals $(p<0.05)$ after lactose. However, post milk challenge only breath $\mathrm{H}_{2}$ was different between LP and LNP individuals $(p<0.05)$, whereas plasma glucose and urinary galactose/creatinine ratio did not differ $(p>0.05)$ (Fig. 1 and Additional File 1: Table S1)). The kinetics of breath $\mathrm{H}_{2}$, plasma glucose and urinary galactose/creatinine ratio between LP and LNP are shown in Additional File 2: Figure S1.

\section{Diagnostic accuracy of malabsorption marker using ROC curve analyses assessed against LCT genotypes}

As the cut-off values described in literature for the malabsorption markers tested vary or have not been well established to specific lactose doses or substrates, the diagnostic accuracy of each malabsorption marker was assessed using ROC curve analyses (Table 3, Additional File 3: Figure S2).

\section{Accuracy with $50 \mathrm{~g}$ lactose}

Following lactose ingestion, breath $\mathrm{H}_{2}$ had 'outstanding' diagnostic accuracy with an $\mathrm{AUC}=1.00$. Comparatively, plasma glucose and urinary galactose/creatinine ratio accuracies were 'acceptable' ( $>0.70$ ) with $\mathrm{AUC}=0.75$ and 0.77 (Table 3). The AUC was significant for all three index measures after the lactose challenge $(p<0.01)$ (Table 3).

\section{Accuracy with milk}

Using milk as a substrate, the accuracy of breath $\mathrm{H}_{2}$ was 'outstanding' with AUC $>0.90$ and $p<0.001$ irrespective of the type of milk consumed (A2M or CON). However, glucose and galactose were 'not reliable' methods to diagnose LNP after milk ingestion with an AUC $<0.70$ and $p>0.05$ (Table 3), so the optimal cut-off for these measures could not be assessed.

\section{ROC curve AUCs}

The AUCs for breath $\mathrm{H}_{2}$ and urinary galactose/creatinine ratio did not differ between lactose or milk ingestion $(p>0.05)$. However, AUCs for glucose differed significantly between lactose and CON milk $(p=0.032)$ and between lactose and A2M ( $p=0.042)$ (Table 3).

\section{Established cut-off value after lactose and milk challenge (A2M and CON Milk)}

The optimal cut-off value for breath $\mathrm{H}_{2}$ after lactose and milk ingestion was determined by ROC curve analyses using the Youden index. The optimal cut-off for breath $\mathrm{H}_{2}$ after ingestion of lactose was $79 \mathrm{ppm}$ providing sensitivity and specificity of $100 \%$; when a statistical outlier was removed the cut off value was reduced to $53 \mathrm{ppm}$ providing the same sensitivity and specificity. The cut-off value following CON milk ingestion was $21 \mathrm{ppm}$ providing a sensitivity of $92 \%$ and specificity of $100 \%$ but for A2M it was 13 ppm, providing the same sensitivity and specificity.

Table 2 Participant demographics

\begin{tabular}{|c|c|c|c|c|}
\hline \multirow[t]{2}{*}{ Measure $^{\mathbf{a}}$} & \multicolumn{2}{|l|}{ LP genotypes ${ }^{\mathbf{b}}$} & \multirow{2}{*}{$\begin{array}{l}\text { LNP genotypes } \\
\text { LNP Homozygote }(n=14) \\
\mathrm{CC}_{13910} / \mathrm{GG}_{22018}\end{array}$} & \multirow{2}{*}{$\begin{array}{l}\boldsymbol{p} \\
\text { value }^{c}\end{array}$} \\
\hline & $\begin{array}{l}\text { LP Homozygote }(n=16) \\
T_{13910} / \mathrm{AA}_{22018}\end{array}$ & $\begin{array}{l}\text { LP Heterozygote }(n=10) \\
\mathrm{CT}_{13910} / \mathrm{GA}_{22018}\end{array}$ & & \\
\hline $\mathrm{BMI}\left(\mathrm{kg} / \mathrm{m}^{2}\right)$ & $22.5 \pm 0.5$ & $22.3 \pm 0.5$ & $24.4 \pm 1.0$ & 0.098 \\
\hline Age (years) & $26.8 \pm 0.6$ & $24.2 \pm 0.96$ & $26.2 \pm 0.68$ & 0.060 \\
\hline Glucose (mmol/L) & $5.52 \pm 0.20$ & $5.15 \pm 0.16$ & $5.5 \pm 0.21$ & 0.758 \\
\hline Triglycerides (mmol/L) & $1.12 \pm 0.11$ & $1.11 \pm 0.09$ & $1.09 \pm 0.09$ & 0.965 \\
\hline Insulin $(\mu \mathrm{U} / \mathrm{mL})$ & $13.39 \pm 3.44$ & $9.94 \pm 1.5$ & $13.64 \pm 3.01$ & 0.687 \\
\hline
\end{tabular}

${ }^{a}$ Glucose, triglycerides and insulin measures in plasma

${ }^{b}$ Values presented as mean \pm SEM. Genotypes for lactase persistence classification taken from $[12,48]$

${ }^{c} p$ value was computed using linear mixed model

$B M I$ body mass index, $L N P$ lactase non-persistence, $L P$ lactase persistence 


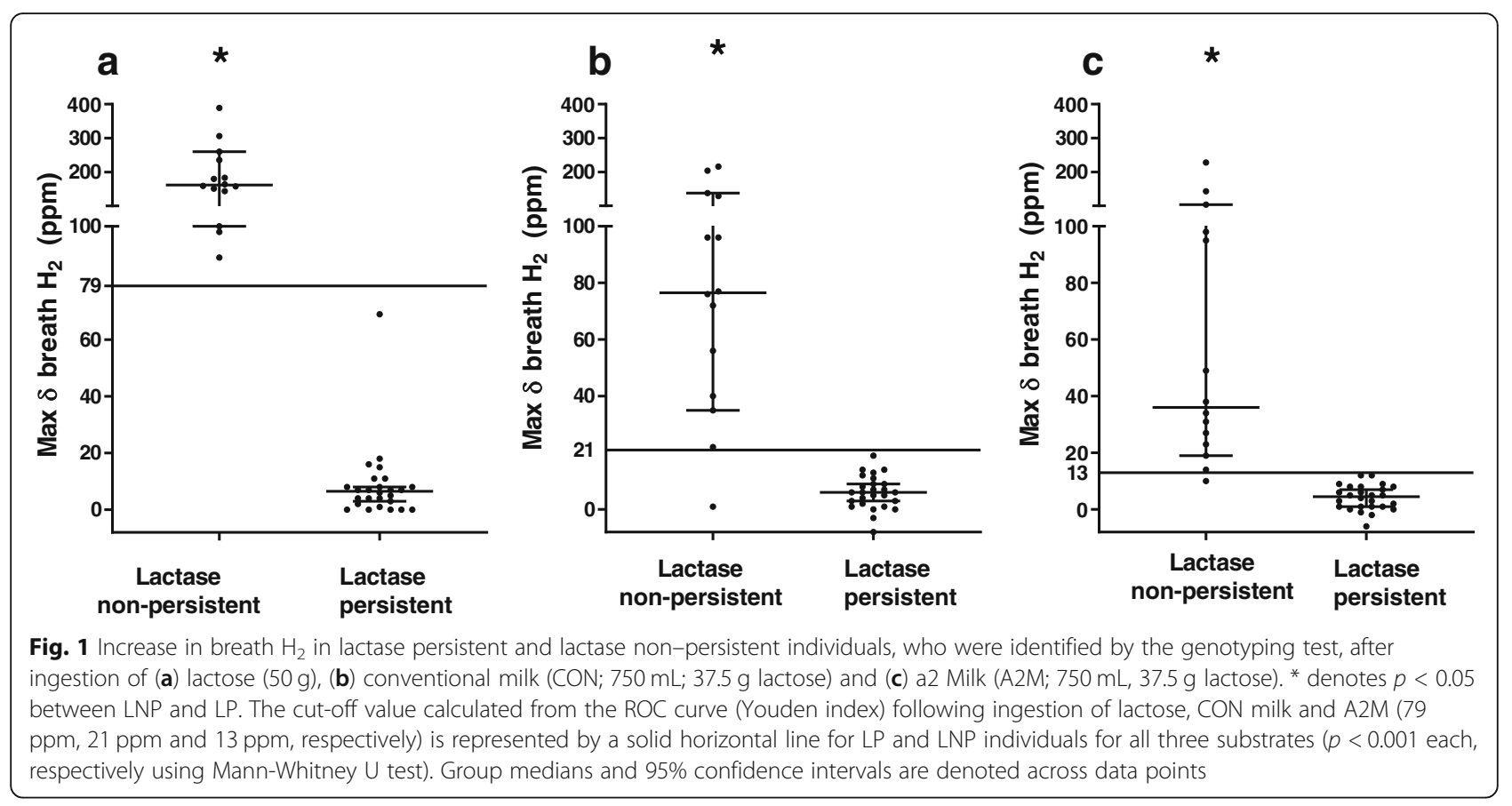

Following lactose ingestion, the cut-off values for plasma glucose and urinary galactose/creatinine ratio were 1.77 $\mathrm{mmol} / \mathrm{L}$ and $0.03 \mathrm{mg} / \mathrm{mg}$, respectively. Although the specificity remained high, sensitivity was lower for both plasma glucose and urinary galactose/creatinine than for breath $\mathrm{H}_{2}$ (Table 3). Since the AUCs for plasma glucose and urinary galactose/creatinine ratio following milk ingestion were $<0.7$, the cut-off values were not calculated.

\section{Validity of malabsorption markers using literature cut-offs assessed against LCT genotype Validity with lactose}

Following lactose ingestion, the validity of malabsorption markers using literature cut-offs (Table 1) to diagnose LNP was assessed against the genotype reference standard. Breath $\mathrm{H}_{2}$ had $100 \%$ sensitivity and $96.2 \%$ specificity for LNP classification. Both the sensitivity and specificity

Table 3 Accuracy of diagnostic measures and substrates for lactose malabsorption

\begin{tabular}{|c|c|c|c|c|c|c|}
\hline Measure $^{\mathbf{a}}$ and substrate ${ }^{\mathbf{b}}$ & $A \cup C^{c}$ & $95 \% \mathrm{Cl}$ & $p$ value $^{d}$ & Cut-offe $^{e}$ & Sensitivity(\%) & Specificity (\%) \\
\hline \multicolumn{7}{|l|}{ Breath $\mathrm{H}_{2}$} \\
\hline Lactose & 1.000 & 1 & $<0.001$ & 79 ppm & 100 & 100 \\
\hline $\mathrm{CON}$ & 0.942 & $0.828-1$ & $<0.001$ & 21 ppm & 92 & 100 \\
\hline $\mathrm{A} 2 \mathrm{M}$ & 0.994 & $0.981-1$ & $<0.001$ & 13 ppm & 92 & 100 \\
\hline \multicolumn{7}{|l|}{ Plasma glucose } \\
\hline Lactose & $0.755^{\mathrm{a}}$ & $0.603-0.907$ & 0.008 & $1.77 \mathrm{mmol} / \mathrm{L}$ & 61 & 100 \\
\hline CON & $0.535^{b}$ & $0.271-0.645$ & 0.671 & NA & NA & NA \\
\hline $\mathrm{A} 2 \mathrm{M}$ & $0.458^{b}$ & $0.348-0.723$ & 0.712 & NA & NA & NA \\
\hline \multicolumn{7}{|c|}{ Urinary galactose/creatinine ratio } \\
\hline Lactose & 0.758 & $0.611-0.905$ & 0.008 & $0.03 \mathrm{mg} / \mathrm{mg}$ & 53 & 100 \\
\hline CON & 0.653 & $0.480-0.838$ & 0.112 & NA & NA & NA \\
\hline $\mathrm{A} 2 \mathrm{M}$ & 0.618 & $0.433-0.803$ & 0.223 & NA & NA & NA \\
\hline
\end{tabular}

${ }^{a}$ Maximal increase in breath $\mathrm{H}_{2}$ and plasma glucose over baseline for $3 \mathrm{~h}$, urinary galactose/creatinine ratio at $3 \mathrm{~h}$ post lactose and milk challenge

${ }^{\mathrm{b}}$ Lactose: $50 \mathrm{~g}$ lactose in $250 \mathrm{~mL}$ water; $\mathrm{CON}$ and A2M: $750 \mathrm{~mL}$ milk

c Values are area under the receiver operating characteristics (ROC) curve (AUC)

Different letters $(a, b)$ represent a significant difference in the AUCs of the ROC curve between substrates calculated by ROC test

${ }^{d} p$ value between calculated ROC AUC and AUC of 0.5 (no discrimination between true positives (TP; LNP) and true negatives (TN; LP)) was computed using the Mann-Whitney $\mathrm{U}$ test

${ }^{\text {e }}$ Cut offs (calculated by the Youden Index) are presented, unless AUC $>0.7$ and $P$ value $<0.05$

A2M a2 milk, CON conventional milk, $\mathrm{Cl}$ confidence interval 
for plasma glucose were below 70\% (Table 4). The urinary galactose values were lower than previous reports, and no subject had a galactose/creatinine ratio above the literature cut-off of $0.1 \mathrm{mg} / \mathrm{mg}$. Thus, urinary galactose/creatinine ratio failed to detect any LP individuals resulting in $100 \%$ sensitivity but $0 \%$ specificity for LNP.

The agreement between the genetic classification and literature-based classification using breath $\mathrm{H}_{2}$ and plasma glucose was significant $(p<0.01 ; \kappa=0.090$ and $\kappa=0.319, p<0.05$ respectively), despite the lower sensitivity and specificity of the plasma glucose. Urinary galactose/creatinine ratio did not agree with the genetic reference standard due to the sample range falling below the literature cut-off.

\section{Validity with milk}

Following milk ingestion, the validity of malabsorption markers to correctly classify LNP was diminished across all malabsorption detection methods used. Validity was assessed using the literature reported cut- offs with and without adjusting for the dose of lactose (Table 4).

The sensitivity of breath $\mathrm{H}_{2}$ was unchanged (i.e. 92.9\%) with or without the adjusted $\mathrm{H}_{2}$ value following CON milk ingestion whereas sensitivity was improved following A2M ingestion with the adjusted $\mathrm{H}_{2}$ value from 78.6 to $85.7 \%$. However, following CON milk ingestion, the specificity decreased from 100 to 96.2\% with the adjusted $\mathrm{H}_{2}$ value although specificity remained unchanged for A2M (100\%). The specificity for plasma glucose was $<58 \%$ with more than 13 false positive results for both types of milk with or without adjustment for lactose dose. However, the specificity was improved from 26.9 to $57.7 \%$ (CON milk) and 38.5 to $46.2 \%$ (A2M) after the adjustment. The sensitivity was slightly reduced from $(64.3 \%$ to 57.1$)$ following A2M ingestion but moreso for CON milk (from 92.9 to $78.6 \%$ ) after the adjustment. For the urinary galactose/creatinine ratio, the concentration was lower than the optimal cut-off with or without adjustments.

Table 4 Performance of diagnostic measures of lactose malabsorption for detection of lactase non-persistence

\begin{tabular}{|c|c|c|c|c|c|c|c|c|c|c|}
\hline Measure $^{a}$ and substrate ${ }^{b}$ & Cut-off used $^{c}$ & Sensitivity (\%) & Specificity (\%) & $\mathrm{FP}(\mathrm{n})$ & $\mathrm{FN}(\mathrm{n})$ & $\mathrm{TP}(\mathrm{n})$ & $\mathrm{TN}(\mathrm{n})$ & PPV (\%) & NPV (\%) & $\mathrm{k}$ index ${ }^{\mathrm{C}}$ \\
\hline \multicolumn{11}{|l|}{ Breath H2 } \\
\hline Lactose & 20 ppm & 100.0 & 96.2 & 1 & 0 & 14 & 25 & 93.3 & 100 & $0.9^{* * *}$ \\
\hline CON - unadjusted & $20 \mathrm{ppm}$ & 92.9 & 100.0 & 0 & 1 & 13 & 26 & 100 & 96.3 & $0.9^{* *}$ \\
\hline CON - adjusted & 15 ppm & 92.9 & 96.2 & 1 & 1 & 13 & 25 & 82.9 & 96.2 & $0.9^{* * *}$ \\
\hline A2M - unadjusted & 20 ppm & 78.6 & 100.0 & 0 & 3 & 11 & 26 & 100 & 89.6 & $0.8^{* * *}$ \\
\hline $\mathrm{A} 2 \mathrm{M}$ - adjusted & 15 ppm & 85.7 & 100.0 & 0 & 2 & 12 & 26 & 100 & 89.7 & $0.8^{* * *}$ \\
\hline \multicolumn{11}{|l|}{ Plasma glucose } \\
\hline Lactose & $1.11 \mathrm{mmol} / \mathrm{L}$ & 64.3 & 69.2 & 8 & 5 & 9 & 18 & 52.9 & 78.2 & $0.3^{*}$ \\
\hline CON - unadjusted & $1.11 \mathrm{mmol} / \mathrm{L}$ & 92.9 & 26.9 & 19 & 1 & 13 & 7 & 40.6 & 87.5 & 0.2 \\
\hline CON - adjusted & $0.83 \mathrm{mmol} / \mathrm{L}$ & 78.6 & 57.7 & 15 & 3 & 11 & 11 & 42.4 & 78.6 & 0.2 \\
\hline A2M - unadjusted & $1.11 \mathrm{mmol} / \mathrm{L}$ & 64.3 & 38.5 & 16 & 5 & 9 & 10 & 36 & 66.7 & 0.02 \\
\hline $\mathrm{A} 2 \mathrm{M}$ - adjusted & $0.83 \mathrm{mmol} / \mathrm{L}$ & 57.1 & 46.2 & 14 & 6 & 8 & 12 & 36.4 & 77.8 & 0.02 \\
\hline \multicolumn{11}{|c|}{ Urinary galactose/creatinine ratio ${ }^{e}$} \\
\hline Lactose & $0.10 \mathrm{mg} / \mathrm{mg}$ & 100.0 & NA & 26 & 0 & 14 & 0 & 35 & NA & 0 \\
\hline CON- unadjusted & $0.10 \mathrm{mg} / \mathrm{mg}$ & 100.0 & NA & 26 & 0 & 14 & 0 & 35 & NA & 0 \\
\hline CON - adjusted & $0.08 \mathrm{mg} / \mathrm{mg}$ & 100.0 & NA & 26 & 0 & 14 & 0 & 35 & NA & 0 \\
\hline A2M- unadjusted & $0.10 \mathrm{mg} / \mathrm{mg}$ & 100.0 & NA & 26 & 0 & 14 & 0 & 35 & NA & 0 \\
\hline A2M- adjusted & $0.08 \mathrm{mg} / \mathrm{mg}$ & 100.0 & NA & 26 & 0 & 14 & 0 & 35 & NA & 0 \\
\hline
\end{tabular}

Classification was based on the genotype reference standard for lactase non-persistence (LNP; $n=14)$ relative to lactase persistent (LP; $n=26$ )

${ }^{a}$ Breath $\mathrm{H}_{2}$, plasma glucose indicates maximal increase in breath $\mathrm{H}_{2}$ and plasma glucose over baseline for $3 \mathrm{~h}$ post lactose and milk ingestion and urinary galactose/creatinine ratio at $3 \mathrm{~h}$ post lactose and milk ingestion

Lactose: $50 \mathrm{~g}$ lactose in $250 \mathrm{~mL}$ water; $\mathrm{CON}$ and $\mathrm{A} 2 \mathrm{M}$ : $750 \mathrm{~mL}$ of milk

${ }^{c}$ Cut-off values for lactose and unadjusted (CON and A2M) were based on ingestion of $50 \mathrm{~g}$ lactose. Adjusted cut-off values were calculated based on ingestion of $750 \mathrm{~mL}$ of milk $37.5 \mathrm{~g}$ of lactose

${ }^{d}{ }_{K}$ represents the Cohen's kappa index indicating the agreement between lactose malabsorption and genotype

Significance indicated as * $p$ value $<0.05,{ }^{* *} p$ value $<0.01,{ }^{* *} p$ value $<0.001$

e Galactose/creatinine ratio concentration range was lower than the threshold of $0.10 \mathrm{mg} / \mathrm{mg}$; no lactose malabsorption was detected by the method using the literature threshold of $0.10 \mathrm{mg} / \mathrm{mg}[28]$ for both CON and A2M

$A 2 M$ a2 milk, CON conventional milk, FN false negative, FP false positive, NPV negative predictive value, $P P V$ positive predictive value, $T N$ true negative, $T P$ true positive. FN and FP represent the total number of false negativeand false positive, respectively out of total $(N=40)$ participants 


\section{Discussion}

This study demonstrated that following either a lactose or milk challenge breath $\mathrm{H}_{2}$ was a reliable method to detect LNP, showing strong agreement (100\%) with genetic polymorphic analysis. Breath $\mathrm{H}_{2}$ was superior to either plasma glucose or urinary galactose/creatinine ratio in the assessment of LNP after both lactose and milk challenge. A marked reduction in accuracy of plasma glucose and urinary galactose/creatinine was observed when milk was used as the challenge substrate. The cut-off calculated after lactose challenge for both breath $\mathrm{H}_{2}$ and plasma glucose was higher $(79 \mathrm{ppm}$ and $1.77 \mathrm{mmol} / \mathrm{L})$ than the literature cut-offs (20 ppm [23-25] and 1.11 $\mathrm{mmol} / \mathrm{L}[12,26])$ whereas urine galactose concentrations were generally 10 fold lower than concentrations previously reported, probably due to variation in the method used resulting in a lower threshold $(0.03 \mathrm{mg} / \mathrm{mg})$ than previously reported $(0.10 \mathrm{mg} / \mathrm{mg})$ [28]. Furthermore, this study demonstrated that $\beta$-casein variation in milk was a further determinant of the breath $\mathrm{H}_{2}$ test performance. A2M exhibited a lower optimal breath $\mathrm{H}_{2}$ threshold for accurate LNP discrimination than CON milk which corresponds to a lower rise in breath $\mathrm{H}_{2}$ observed after A2M compared to CON milk [41].

Breath $\mathrm{H}_{2}$ after a lactose challenge provided a very high sensitivity and specificity to diagnose LNP. This is consistent with previously reported high agreement (90\%) between breath $\mathrm{H}_{2}$ and $\mathrm{C} / \mathrm{T}_{13910}$ genotype, with $97 \%$ specificity and $95 \%$ sensitivity (where breath $\mathrm{H}_{2}$ was the reference standard) [50]. In the current study, plasma glucose exhibited low sensitivity and specificity, consistent with previous reports [11]. Glucose regulation in the body is complex and influenced by gastric emptying, hormonal regulation [10], and absorbed carbohydrate, which may explain the method's lower accuracy. Rapid insulin responses to meals have been shown to result in false positive results, whereas in diabetic patients impaired glucose homeostasis may give false negative results [53]. Similar to glucose, the urinary galactose/creatinine ratio was less accurate than breath $\mathrm{H}_{2}$ as urinary galactose may also be affected by gastrointestinal, hepatic and renal metabolism [29], or by the urine adjustment method (no adjustment [31], creatinine [28], or specific gravity [54]). Moreover, the sensitivity and specificity of urinary galactose could not be reliably assessed due to differences in detection ranges from previous reports [27-29], highlighting the variability of this method. Thus, plasma glucose and urinary galactose are less preferred methods to diagnose LNP with lactose than breath $\mathrm{H}_{2}$.

The accuracy of plasma glucose and urinary galactose/ creatinine ratio in diagnosing LNP after a milk challenge has not yet been reported, although both are used in practice [32, 35]. Based on our ROC curve analysis following milk ingestion, the AUCs for plasma glucose and urinary galactose/creatinine ratio were unreliable $(\mathrm{AUC}<0.70)$ and could not differentiate LP from LNP. The presence of fats and protein in milk is likely to interfere with glucose and galactose metabolism, impacting these measures. The postprandial glucose response to carbohydrate ingested with fats may reduce glucose responses due to fat-induced delayed gastric emptying [55]. Indeed, the blood glucose response to lactose was previously shown to be lower with whole and skim milk than isolated lactose [56]. Studies in rodents showed lowered galactosuria when fat was included in lactosecontaining diets $[57,58]$. These digestive and metabolic influences may explain the poorer accuracy of plasma glucose and urinary galactose/creatinine to reliably diagnose LNP after milk ingestion; the greater risk of false positive results with these methods should be considered prior to their use.

It is important to note that the change in breath $\mathrm{H}_{2}$ depends on the dose of the lactose administered [23]. Lactose doses vary within clinical and research practice, ranging from adjustments per $\mathrm{kg}$ body weight (particularly for children) [59], to standard doses used to ensure LM $(50 \mathrm{~g})[22,60]$, or to approximate realistic doses (e.g., $10 \mathrm{~g}$ [61] to $25 \mathrm{~g}$ [62]). However, the cut-off value is not always dose-adjusted to diagnose LM or LNP. Where milk is used as a substrate, the dose of lactose is likely to be lower, as one serving $(250 \mathrm{~mL})$ of milk has only $12 \mathrm{~g}$ lactose. Our study demonstrated that without a lactose-dose adjustment of the cut-off, the sensitivity of breath $\mathrm{H}_{2}$ using A2M was reduced to 78.6\%, more similar to the sensitivities observed for plasma glucose. With a lactose-dose adjustment of the cut-off, the sensitivity after A2M was improved due to avoidance of one false negative result. However, lactose-dose adjustment did not improve the breath $\mathrm{H}_{2}$ sensitivity following CON ingestion, and rather decreased specificity to $96.2 \%$ due to one false positive. This difference between milks was also evident with the lactose-dose adjustment cutoff for A2M (15 ppm) more closely approximating the calculated cut-off $(13 \mathrm{ppm})$, while for CON some discrepancy remained. Hence, to preserve the sensitivity and specificity of LM detection, even using the highly reliable breath $\mathrm{H}_{2}$, cut-off values should be used that have been validated for the specific dose and substrate of lactose used.

The breath $\mathrm{H}_{2}$ cut-off values calculated from this study, especially after a lactose challenge, were much higher than the literature cut-offs. One reason could be that one LP heterozygous individual had much higher breath $\mathrm{H}_{2}$ than the rest of the group (i.e. outlier); yet, even when this was accounted for, the breath $\mathrm{H}_{2}$ cut-off still remained higher than the literature cut-offs. The calculated cut-off may also have been high due to the 
higher lactose dose used, or the presence of high-grade lactose malabsorbers (breath $\mathrm{H}_{2}$ increase $>70 \mathrm{ppm}$ ) [63]. The use of literature cut-offs however detected lactose malabsorption with $100 \%$ sensitivity, with presence of only 1 FP (which was the heterozygous LP individual). Thus in order to achieve higher sensitivity it is appropriate to use a lower cut off $(20 \mathrm{ppm})$ after lactose challenge.

The milk types used in this study contained either A1 and $\mathrm{A} 2 \beta$-casein (CON milk) or exclusively A2 $\beta$-casein (A2M). Despite having the same quantity of lactose, these milk types resulted in different breath $\mathrm{H}_{2}$ concentrations, different sensitivity for breath $\mathrm{H}_{2}$ to detect LNP and different calculated optimal cut-off values (CON: 21 ppm vs A2M: $13 \mathrm{ppm}$ ). Although milk has been used as a substrate for lactose tolerance testing [32, 35], differences compared to isolated lactose on malabsorption markers $[22,56]$ and the impact of variability of components within milk [56] is not widely reported. The lower sensitivity and cut-off for A2M suggests that the A1 $\beta$ casein content of milk may influence the $\mathrm{H}_{2}$ concentration in breath, which may be a factor to consider when milk is used as a substrate to diagnose LNP using the $\mathrm{H}_{2}$ breath test. The mechanisms leading to a higher cut-off for malabsorption with A1 $\beta$-casein were not determined in the current study, but could be due to gastrointestinal transit differences between $\mathrm{A} 1$ and A2 $\beta$-casein [31, 64], or peptide-mediated mechanisms [65]. The A1 $\beta$-casein content of milk differs between breeds and herds of cows, such that milk produced by pure Asian or African breeds [40] (including Jersey and Guernsey [66]) are usually free from A1 $\beta$-casein (like A2M), unlike European breeds [40] including Holstein Friesian [66] (which are more like CON milk with both $\mathrm{A} 1$ and $\mathrm{A} 2 \beta$-casein). Although A2 gene frequency is higher in Jersey cows (more than 50\%) [67] this may vary between herds [66]. Depending on the region, breed, or even the herd that milk is sourced from, these types of protein variability may impact the cut-off required for accurate diagnosis. This variability suggests that cut-offs specific to the milk substrate used are required, in lieu of a universal optimal value for LM or LNP. Nevertheless, the added risk of false negatives or false positives using alternate substrates should be acknowledged prior to testing.

Two polymorphisms upstream of the $L C T$ gene $(\mathrm{C} /$ $\mathrm{T}_{13910}$ and $\mathrm{G} / \mathrm{A}_{22018}$ ) were used as the reference standard to diagnose LNP $[14,15]$. This method does not detect secondary LM originating from intestinal damage and may be inaccurate for certain populations [16]. The $\mathrm{C} / \mathrm{T}_{13910}$ polymorphism has been studied predominantly in Caucasian populations [13], while the $\mathrm{G} / \mathrm{A}_{22018}$ polymorphism is more prominent in Northern Chinese [68] and Indian populations [15]. As there is limited information on LP SNPs among non-Caucasian populations,
[68] the selection of SNPs, along with the limited diversity, small sample size, and female-only subject pool, remains a limitation for the generalisability of this study. Further, although lactase activity remains with a single LP allele [69] supporting the binary classification of CT/ GA heterozygotes as LP in the current study, it has been reported that $\mathrm{CT}$ heterozygotes have an intermediate level of lactase activity, higher than $\mathrm{CC}$ homozygotes and lower than TT homozygotes [14, 70, 71]. This effect has been shown to result in higher breath $\mathrm{H}_{2}$ in $\mathrm{CT}_{13910}$ heterozygotes compared to $\mathrm{TT}_{13910}$ homozygotes [70] and could explain the lower correlation between LP (C/ $\mathrm{T}_{13910}$ and $\mathrm{TT}_{13910}$ ) and breath $\mathrm{H}_{2}$ compared to the $\mathrm{CC}_{13910}$ genotype reported by others [72]. Thus, genotyping combined with a breath $\mathrm{H}_{2}$ test is likely to provide the best diagnosis of LNP as an alternative to lactase activity in the intestine.

\section{Conclusion}

Breath hydrogen was more reliable to diagnose LNP compared to plasma glucose and urinary galactose/creatinine ratio after a lactose challenge. When milk was used as a substrate, breath $\mathrm{H}_{2}$ was a reliable method to diagnose LNP but plasma glucose and urinary galactose/ creatinine ratio were not reliable when using available cut-off values. However, breath $\mathrm{H}_{2}$ accuracy and optimal cut-off values may depend on the protein content in the milk, as higher A2 $\beta$-casein content reduced the diagnostic threshold relative to lower A2 $\beta$-casein content or lactose alone. Therefore, the diagnostic threshold of even highly reliable malabsorption tests like breath $\mathrm{H}_{2}$ may vary depending on the substrate used.

\section{Additional Files}

\begin{abstract}
Additional File 1: Table S1. Response to lactose and milk ingestion. Table showing group means (lactase persistent and lactase nonpersistent) means of breath $\mathrm{H}_{2}$ concentration, plasma glucose concentration, and urinary galactose/creatinine ratio following lactose $(50 \mathrm{~g})$, conventional milk $(750 \mathrm{~mL})$, or a2 Milk $^{\mathrm{TM}}(750 \mathrm{~mL})$
\end{abstract}

Additional File 2: Figure S1. Pre and postprandial concentration of A) breath $\mathrm{H}_{2}$, B) plasma glucose and C) urinary galactose/creatinine between lactase persistent and lactase non-persistent individuals following ingestion of lactose, $C O N$ milk, and $\mathrm{A} 2 \mathrm{M}$. A) and B) show the timecoure change in breath $\mathrm{H} 2$ and plasma glucose respectively pre and post lactose and milk ingestion. C) shows the urinary galactose/creatinine concentration pre and post lactose and milk ingestion. Comparisons computed by generalised linear mixed model. Interaction between group and time are shown on each plot. ${ }^{*} p<0.05$ between groups as denoted at each timepoint, or across a range of timepoints as indicated.

Additional File 3: Figure S2. The receiver operating characteristic (ROC) curve for breath $\mathrm{H}_{2}$, plasma glucose, and urinary galactose/ creatinine ratio.

\section{Abbreviations}

AUC: Area under the curve; FN: False negative; FP: False positive; LM: Lactose malabsorption; LNP: Lactase non-persistence; LP: Lactase persistence;

LI: Lactose intolerance; NPV: Negative predictive value; PBMC: Peripheral 
blood mononuclear cells; PCR: Polymerase chain reaction; PPV: Positive predictive value; ROC: Receiver operating characteristics; SNP: Single nucleotide polymorphism

\section{Acknowledgements}

We thank our study participants; Jacob Martinsson, Nils Nilsson, Helga Karlström, Soo Min Han and Jenny Mistretta for clinical support; Blake Seers for statistical assistance; and Randall D'Souza and Christine Keven for technical assistance.

\section{Authors' contributions}

AS conducted research, analysed data, performed statistical analysis, and wrote the manuscript. MPGB and DCS designed the study and revised the manuscript. JKP analysed and interpreted the data. AMM designed and conducted the research, wrote the manuscript, and had primary responsibility for final content. All authors approved the final version of the manuscript for submission.

\section{Authors' information}

Not applicable.

\section{Funding}

This study was funded by the New Zealand Ministry of Business, Innovation and Employment (MBIE) through the High-Value Nutrition National Science Challenge (HVN), with co-funding from The a2 Milk Company Ltd. (a2MC). HVN and a2MC had no role in the design or analysis of the study, or in the writing of this article.

\section{Availability of data and materials}

Data described in the manuscript, code book, and analytic code will not be made available because approval has not been granted by subjects.

\section{Ethics approval and consent to participate}

This study was conducted according to the Declaration of Helsinki and approved by the New Zealand Health and Disability Ethics Committees (Reference no.16/STH/175). All participants provided written informed consent.

\section{Consent for publication}

Not applicable.

\section{Competing interests}

AS, MPGB, JKP and AMM have no conflicts to declare. DCS was employed by a2MC from 12 October 2018 to 31 January 2019. This was after the study described here, and all associated analyses reported within this manuscript, had been completed.

\section{Author details}

${ }^{1}$ The Liggins Institute, The University of Auckland, Auckland, New Zealand. ${ }^{2}$ The Riddet Institute, Palmerston North, New Zealand. ${ }^{3}$ Food Nutrition \& Health Team, AgResearch Limited, Palmerston North, New Zealand. ${ }^{4}$ The High-Value Nutrition National Science Challenge, Auckland, New Zealand. ${ }^{5}$ Singapore Institute for Clinical Sciences, Agency for Science, Technology and Research, Singapore, Singapore.

\section{Received: 11 December 2019 Accepted: 17 June 2020}

\section{Published online: 29 June 2020}

\section{References}

1. Suchy FJ, Brannon PM, Carpenter TO, Fernandez JR, Gilsanz V, Gould JB, et al. NIH consensus development conference statement: lactose intolerance and health. NIH Consens State Sci Statements. 2010;27:1-27.

2. Wang $Y$, Harvey $C B$, Hollox EJ, Phillips $A D$, Poulter $M$, Clay $P$, et al. The genetically programmed down-regulation of lactase in children. Gastroenterology. 1998;114:1230-6.

3. Jellema P, Schellevis FG, van der Windt D, Kneepkens CMF, van der Horst HE. Lactose malabsorption and intolerance: a systematic review on the diagnostic value of gastrointestinal symptoms and self-reported milk intolerance. Q J Med. 2010;103:555-72. https://doi.org/10.1093/qjmed/ hcq082.
4. Lomer MCE. Review article: the aetiology, diagnosis, mechanisms and clinical evidence for food intolerance. Aliment Pharmacol Ther. 2015;41:26275. https://doi.org/10.1111/apt.13041.

5. Catassi C, Bai JC, Bonaz B, Bouma G, Calabrò A, Carroccio A, et al. Non-celiac gluten sensitivity: the new frontier of gluten related disorders. Nutrients. 2013:5:3839-53.

6. Brooke-Taylor S, Dwyer K, Woodford K, Kost N. Systematic Review of the Gastrointestinal Effects of A1 Compared with A2 $\beta$-Casein. Adv Nutr. 2017;2: 739-48.

7. Weaver CM. Should dairy be recommended as part of a healthy vegetarian diet? Point Am J Clin Nutr. 2009;89:1634S-7S. https://doi.org/10.3945/ajcn. 2009.267360.

8. Quann EE, Fulgoni VL, Auestad N. Consuming the daily recommended amounts of dairy products would reduce the prevalence of inadequate micronutrient intakes in the United States: diet modeling study based on NHANES 2007-2010. Nutr J. 2015;14:90. https://doi.org/10.1186/s12937-0150057-5.

9. Messer M, Dahlqvist A. A one-step ultramicro method for the assay of intestinal disaccharidases. Anal Biochem. 1966;14:376-92.

10. Newcomer AD, McGill DB, Thomas PJHA. Prospective comparison of indirect methods for detecting lactase deficiency. New Engl J Med. 1975;293:1232-6.

11. Hovde $\varnothing$, Farup PG. A comparison of diagnostic tests for lactose malabsorption--which one is the best? BMC Gastroenterol. 2009;9:82. https://doi.org/10.1186/1471-230X-9-82.

12. Domínguez Jiménez JL, Fernández Suárez A, Muñoz Colmenero AÚ, Fatela Cantillo D, López PI. Primary hypolactasia diagnosis: comparison between the gaxilose test, shortened lactose tolerance test, and clinical parameters corresponding to the C/T-13910 polymorphism. Clin Nutr. 2017;36:471-6. https://doi.org/10.1016/j.clnu.2016.01.006.

13. Enattah NS, Sahi T, Savilahti E, Terwilliger JD, Peltonen $L$, Järvelä I. Identification of a variant associated with adult-type hypolactasia. Nat Genet. 2002;30:233-7. https://doi.org/10.1038/ng826.

14. Enattah NS, Kuokkanen M, Forsblom C, Natah S, Oksanen A, Järvelä I, et al. Correlation of intestinal disaccharidase activities with the $\mathrm{C} / \mathrm{T}-13910$ variant and age. World J Gastroenterol. 2007;13:3508-12.

15. Kuchay RAH, Anwar M, Thapa BR, Mahmood A, Mahmood S. Correlation of G/a -22018 single-nucleotide polymorphism with lactase activity and its usefulness in improving the diagnosis of adult-type hypolactasia among north Indian children. Genes Nutr. 2013;8:145-51.

16. Itan Y, Jones BL, Ingram CJ, Swallow DM, Thomas MG. A worldwide correlation of lactase persistence phenotype and genotypes. BMC Evol Biol. 2010;10. https://doi.org/10.1186/1471-2148-10-36.

17. Villako K, Maaroos $\mathrm{H}$. Clinical picture of hypolactasia and lactose intolerance. Scand J Gastroenterol Suppl. 1994;202:36-54. https://doi.org/10.3109/ 00365529409091743.

18. Ojetti V, Nucera G, Migneco A, Gabrielli M, Lauritano C, Danese S, et al. High prevalence of celiac disease in patients with lactose intolerance. Digestion. 2005; $71: 106-10$

19. Mishkin B, Yalovsky M, Mishkin S. Increased prevalence of lactose malabsorption in Crohn's disease patients at low risk for lactose malabsorption based on ethnic origin. Am J Gastroenterol. 1997:92: 1148-53.

20. Fassio F, Facioni MS, Guagnini F. Lactose Maldigestion, Malabsorption, and intolerance: a comprehensive review with a focus on current management and future perspectives. Nutrients. 2018;10:1599. https://doi.org/10.3390/ nu10111599.

21. Levitt MD. Production and excretion of hydrogen gas in man. N Engl J Med. 1969;281:122-7. https://doi.org/10.1056/NEJM196907172810303.

22. Casellas F, Malagelada JR. Applicability of short hydrogen breath test for screening of lactose malabsorption. Dig Dis Sci. 2003;48:1333-8.

23. Ghoshal UC, Kumar S, Misra A, Mittal B. Lactose malabsorption diagnosed by $50-\mathrm{g}$ dose is inferior to assess clinical intolerance and to predict response to milk withdrawal than $25-\mathrm{g}$ dose in an endemic area. J Gastroenterol Hepatol. 2013;28:1462-8. https://doi.org/10.1111/jgh.12273.

24. Ruzsanyi V, Heinz-Erian P, Entenmann A, Karall D, Müller T, Schimkowitsch A, et al. Diagnosing lactose malabsorption in children: difficulties in interpreting hydrogen breath test results. J Breath Res. 2016;10:016015. https://doi.org/10.1088/1752-7155/10/1/016015.

25. Gasbarrini A, Corazza GR, Gasbarrini G, Montalto M, Di Stefano MBG. H2breath testing for carbohydrate malabsorption. Aliment Pharmacol Ther 2009;29:1-49. https://doi.org/10.1111/j.1365-2036.2009.03951.x. 
26. Brummer R-JM, Karibe M. Lactose Malabsorption. Scand J Gastroenterol. 1993;28:65-9. https://doi.org/10.3109/00365529309101578.

27. Artan R, Bicakci Z, Isitan F. Urinary lactose tolerance test for the detection of lactose malabsorption. Turkish J Gastroenterol. 1998;9:361-5.

28. Grant JD, Bezerra JA, Thompson SH. Assessment of Lactose absorption by measurement of urinary galactose. Am Gastroenterol Assoc. 1989;97:895-9.

29. Vionnet N, Münger LH, Freiburghaus C, Burton KJ, Pimentel G, Pralong FP, et al. Assessment of lactase activity in humans by measurement of galactitol and galactonate in serum and urine after milk intake. Am J Clin Nutr. 2019; 109:470-7.

30. Kurt I, Abou Ghoush MW, Hasimi A, Serdar MA, Kutluay T. Comparison of indirect methods for lactose malabsorption. Turkish J Med Sci. 2003; 33:103-10.

31. Jianqin S, Leiming X, Lu X, Yelland GW, Ni J, Clarke AJ. Effects of milk containing only $\mathrm{A} 2$ beta casein versus milk containing both $\mathrm{A} 1$ and $\mathrm{A} 2$ beta casein proteins on gastrointestinal physiology, symptoms of discomfort, and cognitive behavior of people with self-reported intolerance to traditional cows' milk. Nutr J. 2016;15:35. https://doi.org/10.1186/s12937-016-0147-z.

32. Villiers FP. A standarized milk tolerance test. JClin Gastroenterol. 1987;9: 320-3.

33. Solomons NW, Garcia-lbanez R, Viteri FE. Hydrogen breath test of lactose absorption in adults: the application of physiological doses and whole cow's milk sources. Am J Clin Nutr. 1980;33:545-54.

34. Martini MC, Savaiano DA. Reduced intolerance symptoms from lactose consumed during a meal. Am J Clin Nutr. 1988;47:57-60.

35. He M, Sun J, Jiang ZQ, Yang YX. Effects of cow's milk beta-casein variants on symptoms of milk intolerance in Chinese adults: a multicentre, randomised controlled study. Nutr J. 2017;16:72. https://doi.org/10.1186/ s12937-017-0275-0.

36. Solomons NW, Rosado JL. Sensitivity and Specificity of the Hydrogen Breath-Analysis Test for Detecting Malabsorption of Physiological Doses of Lactose. Clin Chem. 1983;29:545-8.

37. Shrestha A, Prodhan UK, Mitchell SM, Sharma P, Barnett MPG, Milan AM, et al. Validity of a portable breath Analyser (AIRE) for the assessment of lactose Malabsorption. Nutrients. 2019;11:1636. https://doi.org/10.3390/ nu11071636.

38. Labayen I, Forga L, Gonzalez A, Lenoir-Wijnkoop I, Nutr R, Martinez JA. Relationship between lactose digestion, gastrointestinal transit time and symptoms in lactose malabsorbers after dairy consumption. Aliment Pharmacol Ther. 2001;15:543-9. https://doi.org/10.1046/j.1365-2036.2001. 00952.x.

39. Milan A, Hodgkinson A, Mitchell S, Prodhan U, Prosser C, Carpenter E, et al. Digestive responses to fortified cow or goat dairy drinks: a randomised controlled trial. Nutrients. 2018;10:1492. https://doi.org/10.3390/nu10101492.

40. Pal S, Woodford K, Kukuljan S, Ho S. Milk Intolerance, Beta-Casein and Lactose. Nutrients. 2015;7:7285-97. https://doi.org/10.3390/nu7095339.

41. Milan AM, Shrestha A, Karlström HJ, Martinsson JA, Nilsson NJ, Perry JK, et al. Comparison of the impact of bovine milk $\beta$-casein variants on digestive comfort in females self-reporting dairy intolerance: a randomized controlled trial. Am J Clin Nutr. 2019. https://doi.org/10.1093/ajcn/nqz279.

42. Casellas F, Varela E, Aparici A, Casaus M, Rodríguez P. Development, validation, and applicability of a symptoms questionnaire for lactose Malabsorption screening. Dig Dis Sci. 2009;54:1059-65.

43. Schulz KF, Altman DG, Moher D. CONSORT 2010 statement: updated guidelines for reporting parallel group randomised trials. BMJ. 2010;340: 698-702.

44. Milan AM, Pundir S, Pileggi CA, Markworth JF, Lewandowski PA, CameronSmith D. Comparisons of the Postprandial Inflammatory and Endotoxaemic Responses to Mixed Meals in Young and Older Individuals: A Randomised Trial. https://doi.org/10.3390/nu9040354.

45. Waud JP, Matthews SB, Campbell AK. Measurement of breath hydrogen and methane, together with lactase genotype, defines the current best practice for investigation of lactose sensitivity. Ann Clin Biochem. 2008;45(Pt 1):50-8. https://doi.org/10.1258/acb.2007.007147.

46. R Core Team. R Core Team. In: R: a language and environment for statistical computing. Vienna: R Foundation for Statistical Computing; 2013. p. 2013.

47. DW H, Lemeshow S. Applied Logistic Regression. 2nd edition. United stats of America: A Wiley-Interscience Publication; 2000.

48. Matthews S, Waud J, Roberts A, Campbell A. Systemic lactose intolerance: a new perspective on an old problem. Postgrad Med J. 2005;81:167-73. https://doi.org/10.1136/pgmj.2004.025551.
49. Simon R. Specificity, PPV, and NPV for predictive biomarkers. JNCI J Natl Cancer Inst. 2015;107:1-9.

50. Pohl D, Savarino E, Hersberger M, Behlis Z, Stutz B, Goetze O, et al. Excellent agreement between genetic and hydrogen breath tests for lactase deficiency and the role of extended symptom assessment. Br J Nutr. 2018; 104:900-7. https://doi.org/10.1017/S0007114510001297.

51. Trevethan R. Sensitivity, specificity, and predictive values: foundations, Pliabilities, and pitfalls in research and practice. Front Public Heal. 2017;5: 307.

52. Mandrekar JN. Receiver operating characteristic curve in diagnostic test assessment. J Thorac Oncol. 2010;5:1315-6. https://doi.org/10.1097/JTO. OB013E3181EC173D

53. Ugidos-Rodríguez S, Matallana-González MC, Sánchez-Mata MC. Lactose malabsorption and intolerance: a review. Food Funct. 2018;9:4056-68. https://doi.org/10.1039/C8FO00555A.

54. Pearson MA, Lu C, Schmotzer BJ, Waller LA, Riederer AM. Evaluation of physiological measures for correcting variation in urinary output: implications for assessing environmental chemical exposure in children. J Expo Sci Environ Epidemiol. 2009;19:336-42.

55. Collier G, O'Dea K. The effect of coingestion of fat on the glucose, insulin, and gastric inhibitory polypeptide responses to carbohydrate and protein. Am J Clin Nutr. 1983;37:941-4.

56. Leichter J. Comparison of whole milk and skim milk with aqueous lactose solution in lactose tolerance testing. Am J Clin Nutr. 1973;26:393-6.

57. Barki VH, Feigelson $\mathrm{P}$, et al. Factors inflencing galactose utilization. J Biol Chem. 1949;181:565-71.

58. Nieft $L$, Deuel J. The effetc of fat on the absoprtion and utilization of galactose by the rat. J if Biol Chem. 1947;167:521-5.

59. Heyman MB. Lactose intolerance in infants, children, and adolescents. Pediatrics. 2006;118:1279-86. https://doi.org/10.1542/peds.2006-1721.

60. Beyerlein L, Pohl D, Delco F, Stutz B, Fried M, Tutuian R. Correlation between symptoms developed after the oral ingestion of $50 \mathrm{~g}$ lactose and results of hydrogen breath testing for lactose intolerance. Aliment Pharmacol Ther. 2008;27:659-65. https://doi.org/10.1111/j.1365-2036.2008. 03623.x.

61. Seakins JM, Elliott RB, Quested CM, Matatumua A. Lactose malabsorption in Polynesian and white children in the south West Pacific studied by breath hydrogen technique. BMJ. 1987;295:876-8..

62. Carroccio G, Montalto G, Cavera AN. Lactose intolerance and self-reported Milk intolerance: relationship with lactose Maldigestion and nutrient intake clinical and laboratory pearl lactose intolerance and self-reported Milk intolerance: relationship with lactose Maldigestion and nutrient in. J Am Coll Nutr. 2013;17:631-936. https://doi.org/10.1080/07315724.1998.10718813.

63. Argnani F, Di Camillo M, Marinaro V, Foglietta T, Avallone V, Cannella C, et al. Hydrogen breath test for the diagnosis of lactose intolerance, is the routine sugar load the best one? World J Gastroenterol. 2008;14:6204-7.

64. Barnett MPG, McNabb WC, Roy NC, Woodford KB, Clarke AJ. Dietary A1 $\beta$ -casein affects gastrointestinal transit time, dipeptidyl peptidase-4 activity, and inflammatory status relative to A2 $\beta$-casein in Wistar rats. Int J Food Sci Nutr. 2014;65:720-7. https://doi.org/10.3109/09637486.2014.898260.

65. Haq MRU, Kapila R, Sharma R, Saliganti V, Kapila S. Comparative evaluation of cow $\beta$-casein variants (A1/A2) consumption on Th2-mediated inflammatory response in mouse gut. Eur J Nutr. 2014;53:1039-49. https:// doi.org/10.1007/s00394-013-0606-7.

66. CAK B. Discussions of Effect A1 and A2 Milk Beta-Casein Gene on Health. Appro Poult Dairy Vet Sci. 2018;3. https://doi.org/10.31031/APDV.2018.03. 000556.

67. Behera R, Sahu A, Mandal A, Rai S, Karunakaran M, Dutta T. A1 versus A2 Milk- Impact on Human Health. Int J Livest Res. 2018, 1. https://doi.org/10. 5455/ijlr.20170810113426.

68. Xu L, Sun H, Zhang X, Wang J, Sun D, Chen F, et al. The-22018A allele matches the lactase persistence phenotype in northern Chinese populations. Scand J Gastroenterol. 2010;45:168-74. https://doi.org/10.3109/ 00365520903414176

69. Bulhões AC, Goldani HAS, Oliveira FS, Matte US, Mazzuca RB, Silveira TR. Correlation between lactose absorption and the C/T-13910 and G/A-22018 mutations of the lactase-phlorizin hydrolase (LCT) gene in adult-type hypolactasia. Brazilian J Med Biol Res. 2007;40:1441-6. https://doi.org/10 1590/S0100-879X2007001100004.

70. Dzialanski Z, Barany M, Engfeldt P, Magnuson A, Olsson LA, Nilsson TK. Lactase persistence versus lactose intolerance: is there an intermediate 
phenotype? Clin Biochem. 2016;49:248-52. https://doi.org/10.1016/J. CLINBIOCHEM.2015.11.001.

71. Seppo L, Tuure T, Korpela R, Järvelä I, Rasinperä H, Sahi T. Can primary hypolactasia manifest itself after the age of 20 years? A two-decade followup study. Scand J Gastroenterol. 2008;43:1082-7. https://doi.org/10.1080/ 00365520802095485.

72. Högenauer C, Hammer HF, Mellitzer K, Renner W, Krejs GJ, Toplak H. Evaluation of a new DNA test compared with the lactose hydrogen breath test for the diagnosis of lactase non-persistence. Eur J Gastroenterol

Hepatol. 2005;17:371-6. https://doi.org/10.1097/00042737-200503000-00018.

\section{Publisher's Note}

Springer Nature remains neutral with regard to jurisdictional claims in published maps and institutional affiliations.

Ready to submit your research? Choose BMC and benefit from:

- fast, convenient online submission

- thorough peer review by experienced researchers in your field

- rapid publication on acceptance

- support for research data, including large and complex data types

- gold Open Access which fosters wider collaboration and increased citations

- maximum visibility for your research: over $100 \mathrm{M}$ website views per year

At BMC, research is always in progress.

Learn more biomedcentral.com/submissions 